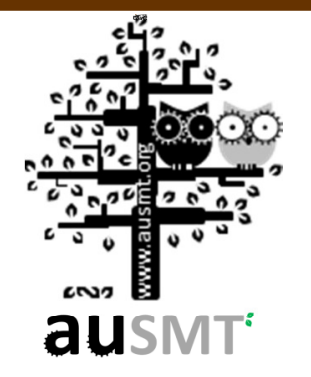

\title{
The Intelligent Automation Demands of Taiwanese Companies with Businesses in Taiwan and Mainland China
}

\section{Tai, Ying-Mei*}

Researcher, Industrial Economics and Knowledge Research Center, Industrial Technology Research Institute, Taiwan

(Received 1 August 2014; Published on line september 1 2014)

*Corresponding author: mandylo@itri.org.tw

DOI: 10.5875 /ausmt.v4i3.840

Most Taiwanese companies invest in Mainland China due to its cheap and a great deal of labor force, or production flexibility. Facing that Mainland China's labor conditions undergo sudden discontinuity, Taiwanese firms with businesses in Taiwan and Mainland China have to change their business models in order to overcome the current difficulties, and create new opportunities. This study shows that the "manufacturing process of the manufacturing industry" is the most important automation item for Taiwanese firms with businesses in Taiwan and Mainland China, followed by "system integration of the manufacturing industry" and "product design of the manufacturing industry", etc. Nearly $60 \%$ of these companies have further intelligent automation requirements, and they may combine several methods such as "self-develop" and "collaborate with other companies".

\section{Introduction}

In response to the change of Mainland China's role as the world's factory, the development of second and third tier cities has created job opportunities. Furthermore, the inability of the one-child generation born in the 1980s and 1990s to endure hardship has caused labor shortage problems in Mainland China. Such problems cannot be ignored by Taiwanese companies with businesses in Taiwan and Mainland China. Whether intelligent automation could be adopted to improve the situation deserves to be explored.

\section{Methodology}

This research uses Taiwan listed companies with businesses in Taiwan and Mainland China as the population, and issued 913 questionnaires, supplemented by an official document from the Industrial Technology Research Institute to increase the response rate. Telephone follow-ups were performed one week after the questionnaires were issued. 108 valid questionnaires were returned, out of which 10 companies are intelligent automation suppliers, 79 are intelligent automation users, while 19 are both intelligent automation suppliers and users (see as Table 1 ). The 
study uses descriptive statistic method for analysis, including the current status of intelligent automation technology/service, the intelligent automation requirements, etc.

Table 1. Statistics of questionnaires issued and returned

\begin{tabular}{|ll|l|}
\hline Item & Specific content \\
\hline $\begin{array}{l}\text { 1. } \\
\text { sumber of companies }\end{array}$ & 913 companies \\
\hline 2. & $\begin{array}{l}\text { Number of companies } \\
\text { responded }\end{array}$ & 108 companies \\
\hline 3. & Response rate & $12 \%$ \\
\hline
\end{tabular}

Source: Industrial Technology Research Institute IEK (July 2014)

\section{Findings}

\section{Current status of intelligent automation}

The study categories intelligent automation into 8 dimensions: (1) product design of the manufacturing industry; (2) manufacturing process of the manufacturing industry; (3) logistics storage and transportation of the manufacturing industry; (4) system integration of the manufacturing industry; (5) business service; (6) health care; (7) intelligent living; and (8) others. Each dimension can be further divided into 4 to 10 sub-dimensions.

The study shows that "manufacturing process of the manufacturing industry" is the most widespread applications by the companies, with a percentage of $72 \%$, as most of these Taiwanese companies are in the manufacturing industry, and are actively seeking countermeasures to combat the changing business environment. The second highest is "system integration of the manufacturing industry" (69\%). Besides the above reasons, it could also be due to the global competitive pressure in the manufacturing industry. These Taiwanese companies need to have system integration capabilities in order to discover the problems in the manufacturing black box. Besides effective use of manpower, it can also increase product quality, enhance production efficiency and strengthen accuracy.

The third is "product design of the manufacturing industry" (58\%), which is mainly from the innovation needs for customized products. Without quick product design capabilities, creating more added-value would be impossible. Following are logistics storage and transportation of the manufacturing industry (56\%), business service (36\%), intelligent living (28\%), etc., as shown in Figure 1.

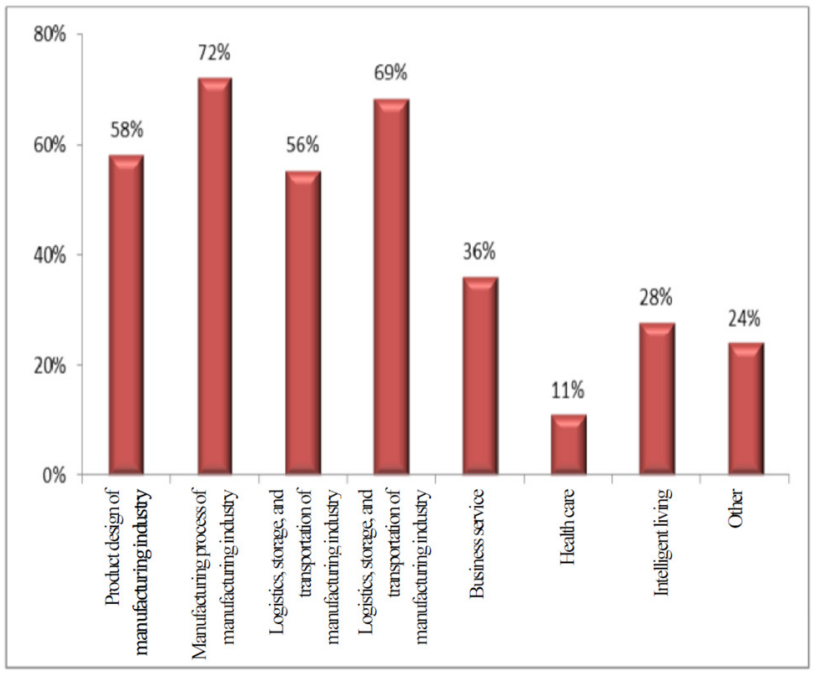

Note:

1. There are 108 valid samples; answered using checkboxes

2. Percentage $=$ Number of responded samples / Number of valid samples

Source: Industrial Technology Research Institute IEK (July 2014)

Figure 1. Statistics of intelligent automation for Taiwanese companies with businesses in Taiwan and Mainland China

The main sub-dimensions of each dimension are:

(1). "Product design of the manufacturing industry": computer-aided design (CAD), engineering database and software interface, engineering information and network technology, etc.

(2). "Manufacturing process of the manufacturing industry": online automatic inspection, automated production system planning, quality control techniques, etc.

(3). "Logistics storage and transportation of the manufacturing industry": plant layout and planning, automated warehouse system, logistics transportation system, etc.

(4). "System integration of the manufacturing industry": connectivity between departments, connectivity between network system and hardware, MIS planning and design, etc.

(5). "Business service": product database building and management, automated system planning of business service, automated logistics system, etc.

(6). "Health care": remote and home care monitoring and data transmission, health care automated 
integration system, health care automated planning system, etc.

(7). "Intelligent living": network system building, intelligent living software information service, integration of information \& communication and sensor technology, etc.

(8). "Others": sensors, controllers, industrial robots, etc.

\section{Intelligent automation requirements}

From the intelligent automation requirements of the responded companies, 43 companies think that there is no such requirement $(40 \%)$, out of which nearly $90 \%$ think that the current technology is sufficient; 64 companies think that there is a need for intelligent automation (60\%), as shown in Figure 2.

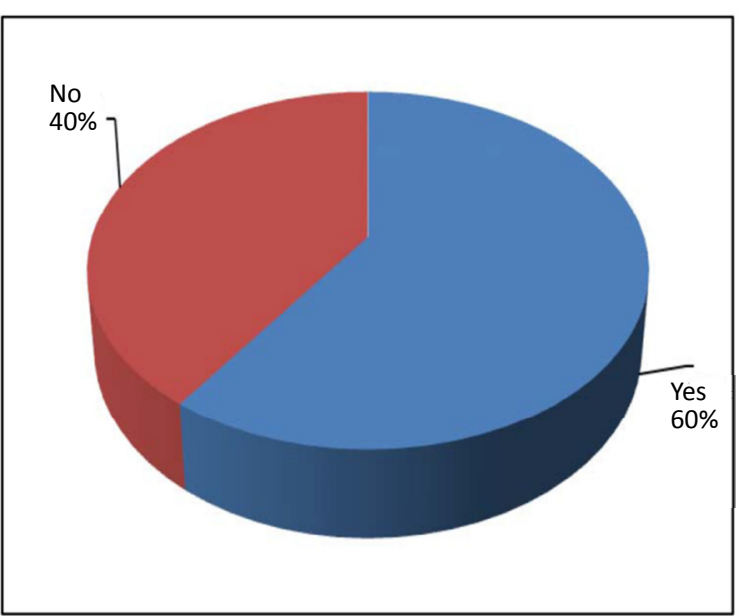

Note: One responded company did not fill in the questionnaire; hence the total number of companies is 107.

Source: Industrial Technology Research Institute IEK (July 2014)

Figure 2. Statistics of intelligent automation demands for Taiwanese companies with businesses in Taiwan and Mainland China

The type of intelligent automation method to be adopted varies across companies. Most companies adopt multiple methods, especially "self-developed" methods, which stands at $70 \%$ of the total number of companies. This is due to the high correlation between intelligent automation and enterprise competitiveness. Most companies handle on their own and set up in-house automation department. 56\% companies will "collaborate with other companies", where the main reason is to tap on external expertise or because there is no economies of scale by setting up their own intelligent automation department. $30 \%$ of the total number of companies will "collaborate with the academia" while $26 \%$ of the total number of companies will "bring in foreign technologies", and such companies have requirements that could not be fulfilled by current technologies. The details are shown in Figure 3.

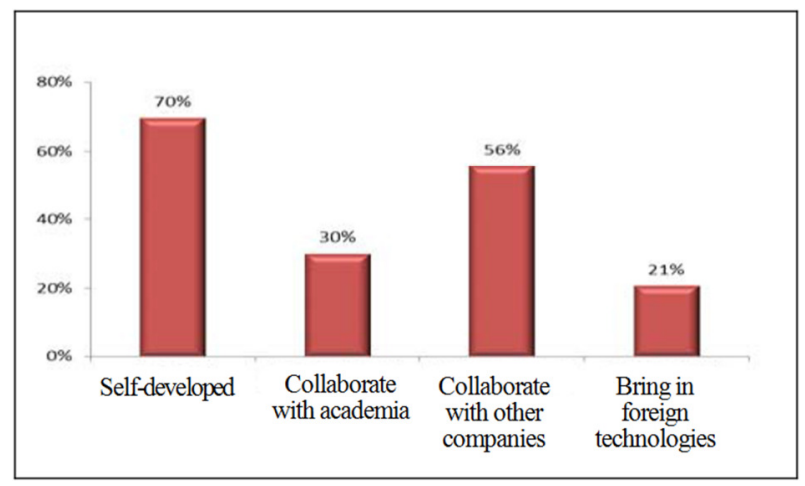

Note:

1. There are 108 valid samples; answered using checkboxes

2. Percentage $=$ Number responded $/$ Number of valid samples

Source: Industrial Technology Research Institute IEK (July 2014)

Figure 3. Methods of fulfilling intelligent automation requirements for Taiwanese companies with businesses in Taiwan and Mainland China

\section{Conclusions}

Most Taiwanese companies invest in Mainland China due to its cheap and a great deal of labor force, or production flexibility. Facing that Mainland China's labor conditions undergoing sudden discontinuity, Taiwanese firms with businesses in Taiwan and Mainland China have to change their business models in order to overcome the current difficulties, and create new opportunities.

Besides shifting to another region or country with cheaper labor, intelligent automation can be considered as an important solution, especially with the rapid progress of the sensors' technologies, as well as the continued popularity of supporting systems such as cloud computing and intelligent software, allowing intelligent automation to be used in more fields of application. Companies who adopt intelligent automation will bear a relatively lower investment cost, and can choose to collaborate with different types of suppliers based on the maturity of their required technology. 